\title{
Sulfate and Calcium Chloride Resistance of Steel/Glass Fiber-Reinforced Polymer Hybrid Panel for Improved Movable Weir Application
}

\author{
S.-K. Lee, ${ }^{1}$ S.-Y. Yoo, ${ }^{2}$ and C.-G. Park ${ }^{2}$ \\ ${ }^{1}$ Department of Bio-Industry Mechanical Engineering, Kongju National University, Yesan, Republic of Korea \\ ${ }^{2}$ Department of Rural Construction Engineering, Kongju National University, Yesan, Republic of Korea \\ Correspondence should be addressed to C.-G. Park; cgpark@kongju.ac.kr
}

Received 24 December 2016; Revised 9 April 2017; Accepted 11 April 2017; Published 4 May 2017

Academic Editor: Joao M. L. Reis

Copyright (c) 2017 S.-K. Lee et al. This is an open access article distributed under the Creative Commons Attribution License, which permits unrestricted use, distribution, and reproduction in any medium, provided the original work is properly cited.

\begin{abstract}
This study evaluated the performance of a hybrid panel that can overcome the current problem of corrosion of the steel panels of improved movable weirs when they are exposed to a sulfate and calcium chloride environment such as sea water. A hybrid panel with glass fiber-reinforced polymer (GFRP) layers on both sides of a steel panel means that the central panel is not exposed to the external elements, which can avoid corrosion problems. In this study, to maximize the hybrid panel's strength and durability, the moisture absorption characteristics and the durability in an accelerated environment were evaluated. The test results were considered to indicate no durability issues as the final absorption ratio was approximately $2.0 \%$ or less in all environments. Also, from the accelerated deterioration test results when the steel panel processed by sand blasting was applied in all accelerated deterioration environments, it satisfied the residual strength level of $65 \%$ or more. However, in the case without surface processing, upon exposure to $\mathrm{MgSO}_{4}$ solution, it did not satisfy the standard residual strength level of $65 \%$. These results show that sand blasting on the surface of a steel panel is adequate for hybrid panels for improved movable weirs.
\end{abstract}

\section{Introduction}

A weir installed across a river can ensure maintenance of the water resource at normal times and also ensure the sufficient passage of water at times of flooding [1-6]. However, a fixed weir causes overflow at the upper side during flooding, which is associated with problems such as degradation of river water flow capacity by the accumulation of soil $[5,6]$. Therefore, such weirs have been replaced by movable ones $[1,2,5,7]$. Movable weirs are required not only for the purposes of using and controlling rivers but also in various fields such as water resource management and water-friendly space composition and for small hydraulic power plants [4-12]. Movable weirs installed in rivers are largely classified into three types: a rubber weir using the air supply/discharge method, a hydraulic steel flipping gate, and a mixed air bag and steel plate gate improved movable weir $[2,4-6]$. A rubber weir is a pneumatic movable weir using an air supply/discharge method, which has less strength than a steel plate gate $[2,5]$.
Whilst it is an environmentally friendly option given the lack of emission of polluting substances and the pneumatic steel plate flipping gate has outstanding durability, it does have the potential disadvantage of river contamination due to the pneumatic oil that is used $[2,5,6]$. The improved movable weir supplements the advantages and disadvantages of the rubber weir and the conduction gate and uses both an inflatable air bag and a steel plate $[5,6]$. Figure 1 shows the form of the improved movable weir. The improved movable weir uses steel panels for all parts except the air bag, so it is potentially associated with the issue of corrosion via contact with the river (Figure 2). This is in turn associated with various problems, such as decreased long-term durability and also damage to the river ecosystem by the leakage of corrosives $[5,6]$. Steel panels also have the additional problem of the degradation of sites at which they are used, such as via increased use of heavy equipment due to their weight and a longer weir construction period $[5,6]$. In this context, a shift to a lighter material, such as composite materials, is 




(a) Photo of improved movable weir

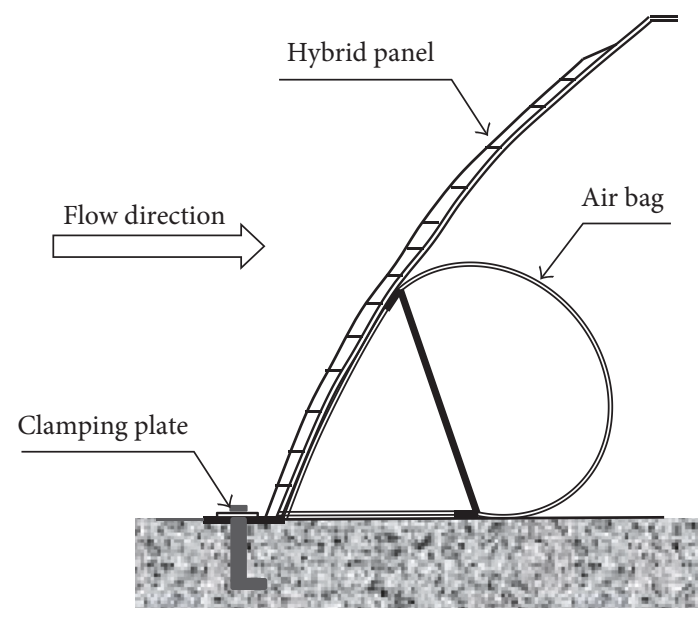

(b) Schematic of improved movable weir

FIGURE 1: System of improved movable weir.

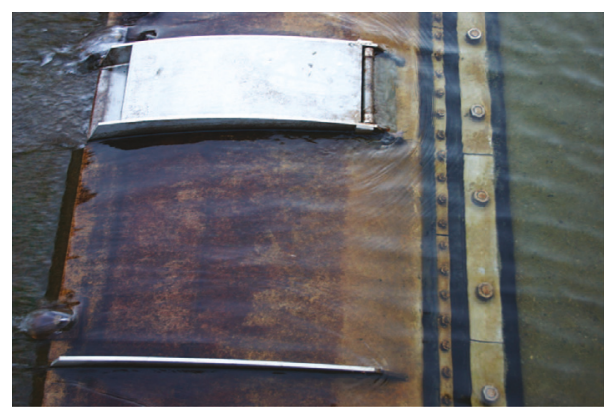

Figure 2: Corrosion of steel panels.

desirable [13]. Composite materials are resistant to corrosion and highly durable, indicating that they fundamentally overcome the problems associated with the deterioration of concrete, which is currently a widely used construction material [13-22]. Such materials can also avoid the problems linked to the corrosion of steel, which can decrease maintenance costs, reduce the weight of the structure given their lightweight characteristics, and also shorten the construction period [13, 16-19]. It is an urgent issue to resolve the problems regarding the life cycles and safety of existing steel plate movable weirs and to reduce the maintenance costs by replacing the steel panels of the improved movable weirs with new material. This is especially true for improved movable weirs, for which there are concerns about exposure to a sulfate and calcium chloride environment linked to steel panel corrosion. The performance of movable weirs exposed to a sulfate and calcium chloride environment may decrease markedly via the activation of corrosion through sulfate and calcium chloride reactions with acid and sulfate ions. This study involves an effort to develop a hybrid panel with the structure of layers of GFRP material on both sides of a steel panel, to replace the existing steel panels. Another goal is to apply these panels as the top panels of improved movable weirs. The GFRP material forms the coating of steel panels to prevent exposure to the external elements, thereby resolving the issue of the corrosion of panels partially exposed to sea water.

There have been many studies on hybrid panels using steel panels and GFRP panels [23-28]. Most of these studies have been carried out to increase elastic modulus by bonding steel panels to solve the problem of low stiffness of GFRP panels $[23,24,26]$. Studies using adhesives to improve the adhesion of steel panels and GFRP panels have been performed [24]. In order to solve the corrosion of steel, a study was carried out to prevent direct exposure of steel by attaching GFRP panel to the exposed part of steel $[23,24]$. In this study, however, hybrid steel/GFRP panels were applied to structures that are always in contact with water. Also, the surface shape of the steel panel was changed to improve the bond properties. Considering the characteristics of the improved movable weir that all surfaces are in contact with water, we applied the method of placing the steel panel in the center and positioning the GFRP panel on both sides when manufacturing the hybrid panel. When the manufactured steel panel and GFRP panel are attached, moisture is continuously put on the bonding surface, resulting in a decrease in durability $[25,28]$. Therefore, there is a need for a method for manufacturing steel panel and GFRP panel in unified methods, rather than bonding manufactured products. The hybrid panel developed 


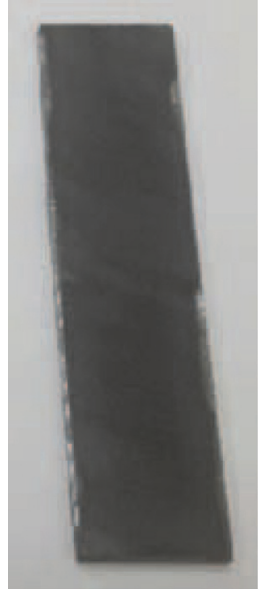

(a) Control

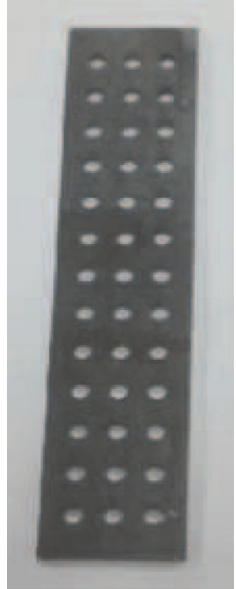

(b) Hole

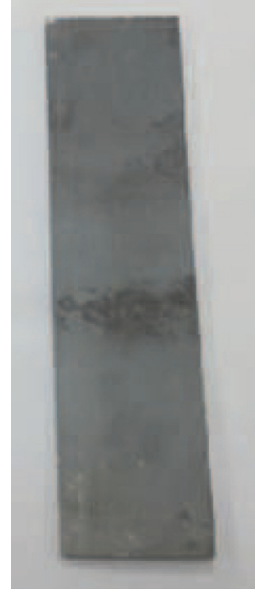

(c) Scratch



(d) Sand blast

FIGURE 3: Surface geometry of steel panels.

TABLE 1: Mechanical properties of steel, glass fiber, and matrix resin.

\begin{tabular}{lccc}
\hline Mechanical properties & Steel panels & $\begin{array}{c}\text { Vinyl ester } \\
\text { resin }\end{array}$ & E-glass \\
\hline Yield stress $(\mathrm{MPa})$ & 330 & 90 & 1,890 \\
Elastic modulus $(\mathrm{GPa})$ & 2,00 & 3.4 & 71 \\
Ultimate strain $(\%)$ & 26 & 5.2 & 2.64 \\
Fiber density $\left(\mathrm{g} / \mathrm{cm}^{3}\right)$ & 7.8 & - & 2.62 \\
Fiber diameter $\left(10^{-6} \mathrm{~m}\right)$ & - & - & 16.5 \\
\hline
\end{tabular}

in this study has the structure of a mixture of two materials with different properties, to maximize the hybrid panel's strength and durability. This study thus evaluated the strength characteristics produced by the surface processing of the material, the moisture absorption characteristics, and the durability in an accelerated sulfate environment.

\section{Materials and Manufacturing of the Steel/GFRP Hybrid Panels}

2.1. Materials. To manufacture the hybrid panels, a general steel panel and E-glass fiber were used, which were bonded together using a vinyl ester resin. The steel panel is made of rolled steel for general structure. Table 1 shows the characteristics of each of the steel, E-glass fiber, and vinyl ester resin that were used in the hybrid steel/GFRP panel. The mixing ratio of E-glass fiber and vinyl ester resin, as a volume ratio, was $40: 60$, respectively. At the time of this study, hybrid panel manufacture conventionally involves a maximum proportion of fiber within the mixture of $40 \%$, so this level was used here. To maximize the hybrid panel's adhesion characteristics, the adhesion strength between the steel panel and the GFRP material is particularly important. This study involved an attempt to increase the adhesiveness between the steel panel and the GFRP material by processing the steel panel surface at the same time using four different methods. Figure 3(a) shows the state without any surface processing, Figure 3(b) shows that blasted sand adhered to the surface, Figure 3(c) shows hole processing of the steel surface, and Figure 3(d) shows rough surface processing by making scratches on the surface with sandpaper. The test specimen was manufactured with a steel panel thickness of $3.2 \mathrm{~mm}$ and a GFRP panel thickness of $6 \mathrm{~mm}, 9 \mathrm{~mm}$, and $12 \mathrm{~mm}$ ( $3 \mathrm{~mm}, 4.5 \mathrm{~mm}$, and $6 \mathrm{~mm}$ on each side).

2.2. Manufacturing Steel/GFRP Hybrid Panels. Figure 4 shows the processing of the manufactured hybrid panel test specimen. When the glass fibers are arranged in one direction, fracture may occur by splitting, so a method of layering the glass fiber sheets in a grid shape was applied. Every time a glass fiber sheet was layered, vinyl ester resin was sprayed, and when the bottom glass fiber panel layering was performed, the steel plate was placed in the middle, and grid-shaped glass fiber sheets were layered in the same way on top to complete the test specimen. Figure 5 shows the actual size of the manufactured hybrid panel.

\section{Accelerated Environment Conditions}

3.1. Tap Water Immersion. To consider the effect of sulfate damage on a hybrid panel-installed improved movable weir in a neutral environment, in addition to an environment containing sulfate ions, panel immersion in tap water at $60^{\circ} \mathrm{C}$ for 50 days was performed.

3.2. Sulfate Solution Immersion. The main reason for applying the hybrid panels to improved movable weirs is to resolve the problem of corrosion, which occurs when steel products are used. Therefore, a hybrid panel that has excellent resistance against sulfate damage could be used to replace the steel panels in improved movable weirs exposed to sulfate in the environment. As an experiment to evaluate the influence of sulfate damage on a hybrid panel, after immersion in a sulfate 


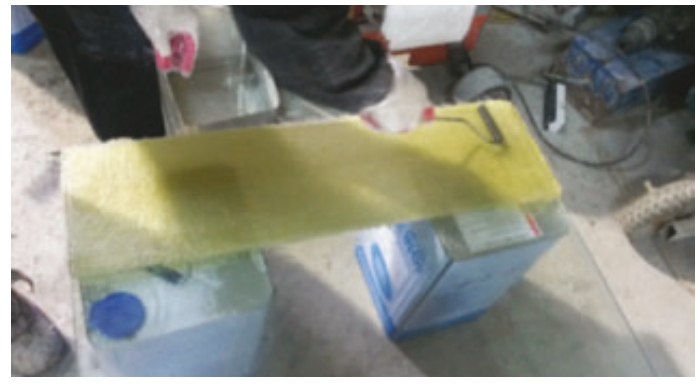

(a) Lower glass fiber laminate

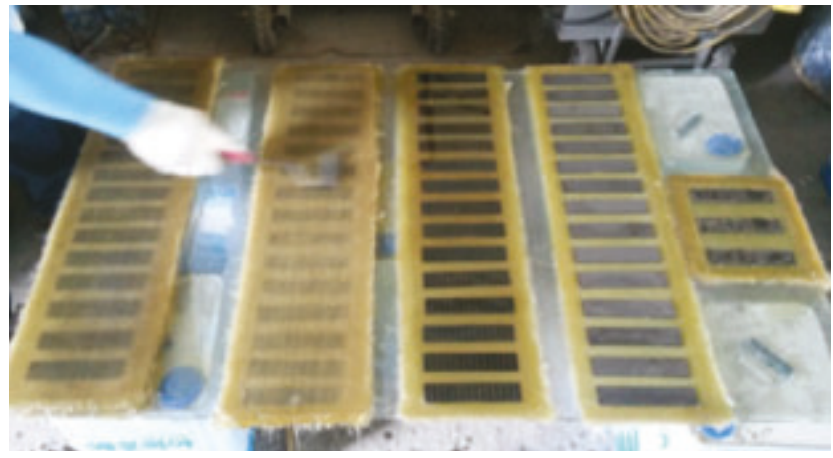

(c) Top glass fiber laminate

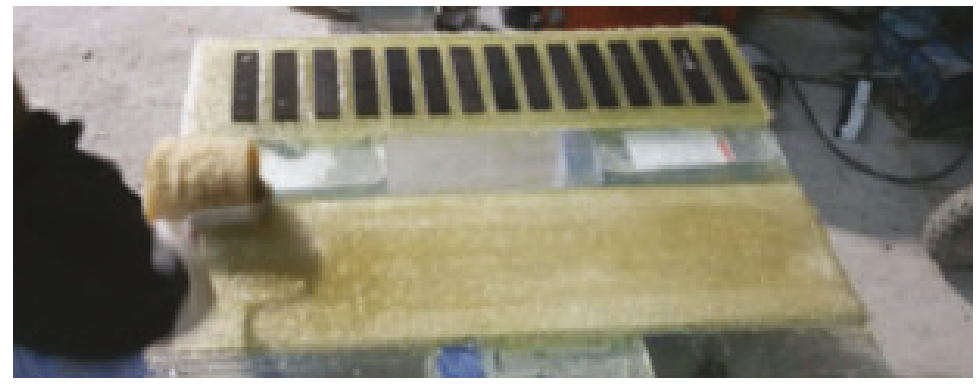

(b) Steel panel installation

FIGURE 4: Manufacturing process of hybrid panels.


Figure 5: Photo of hybrid panels.

solution for a certain period, the decrease in the strength of the panel was measured. Specifically, in this study, to evaluate the influence of sulfate damage on the hybrid panel, it was exposed at $60^{\circ} \mathrm{C}$ to a $10 \%$ solution of $\mathrm{Na}_{2} \mathrm{SO}_{4}$ and a $10 \%$ solution of $\mathrm{MgSO}_{4}$ for 50 days, as an accelerated deterioration test.

3.3. Calcium Chloride Solution Immersion. This experiment involved consideration of the case of exposure to calcium chloride used as deicer on roads near rivers at which hybrid panel-installed improved movable weirs could be installed. Specifically, panels were exposed to a $4 \% \mathrm{CaCl}_{2}$ solution at $60^{\circ} \mathrm{C}$ for 50 days, as another accelerated deterioration test.

\section{Test Methods}

4.1. Absorption. This study also featured a moisture absorption test in which the hybrid panel was exposed to an



(d) Photo of hybrid steel/GFRP panel 


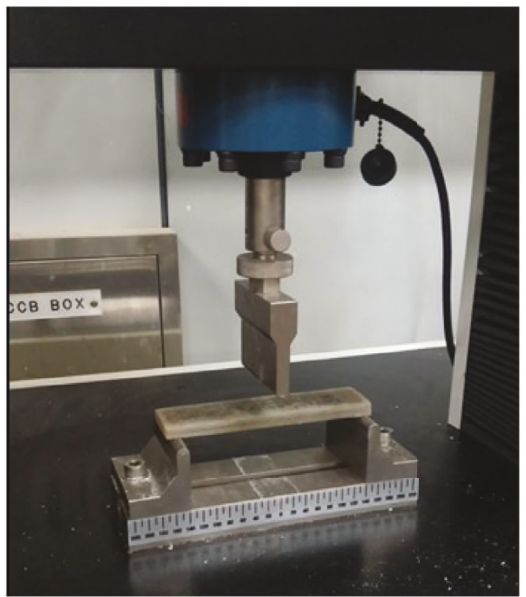

FIgURE 6: Flexural test setup.

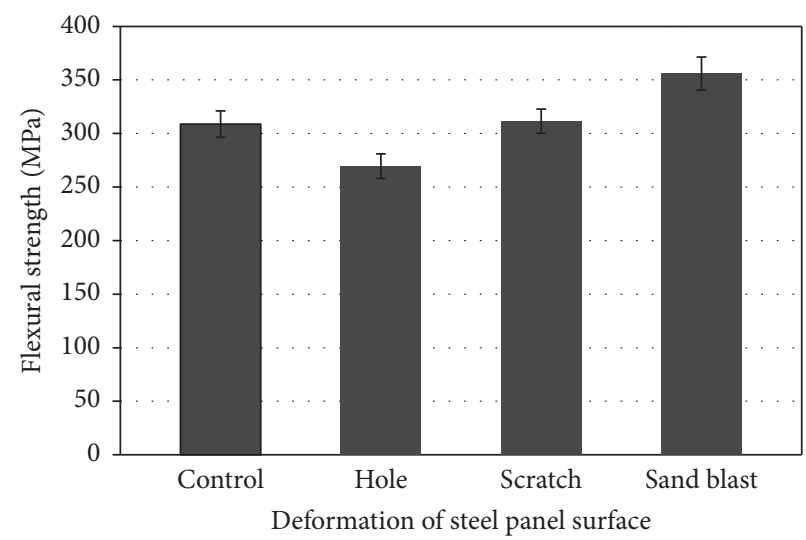

FIgURE 7: Flexural strength test results of deformation of steel panel surface.

GFRP panels on hybrid panels. Also, it was difficult to select a method to prevent bond fracture between the attachment surface of the jig (test machine systems) and the hybrid panel before the bond failure occurred on the adhesion surface of the hybrid panel in the bond test. Therefore, in this study, the flexural strength of the hybrid panel was evaluated because the hybrid panel was subjected to the flexural load. Then, the fracture shape between steel panel and GFRP panel adhesion interface was analyzed and the bond force according to the change of steel panel shape was evaluated. A flexural test was carried out according to ASTM D: 7264/D 7264M-07 (Standard Test Method for Flexural Properties of Polymer Matrix Composite Materials) (Figure 6). The test specimen had a prismatic shape and was $40 \times 40 \times 160 \mathrm{~mm}$ in size. This experiment evaluated the mechanical performance regarding residual strength after exposure of the hybrid panel to an accelerated deterioration environment. In this study, residual strength of $65 \%$ or more was considered to reflect good durability because, according to the study by Nanni et al., if a GFRP composite material composed of glass fiber is applied as a concrete-reinforcing material, it should have $65 \%$ or more residual strength after exposure to an alkali environment $[13,22]$.

\section{Results and Discussion}

5.1. Test Results according to Surface Treatment Method. The flexural strength test results depending on the surface processing method are shown in Figure 7. The flexural strength test results for the test specimen (control) with no surface processing, the test specimen (hole) with a hole in its surface, the test specimen (scratch) with scratches on its surface, and the sand blasted test specimen (sand blast) were 308.80, 269.50, 311.53, and 355.91 MPa, respectively, showing that the sand blasted test specimen's flexural strength was the highest. These results show that the sand blasted test specimen had the highest bonding capacity with the GFRP panel. The test specimen (hole) with the hole in its surface showed the lowest strength. This was caused by the fact that, during the steel panel's surface processing, the test specimen with a hole in its surface has a loss of area, which decreases the steel panel's strength. After the flexural test, the fracture shape appears to be of three types (Figure 8). The first type is when the interface bonding between the steel panel and the GFRP panel is weak and the interface delamination occurs before the cracks due to the flexural load occur (Figure 8(a)). In the second type, interface delamination occurs from the cracked 


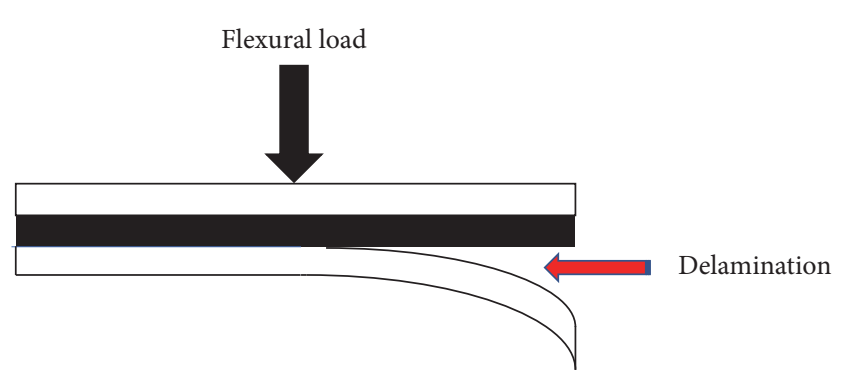

(a) Delamination before cracking

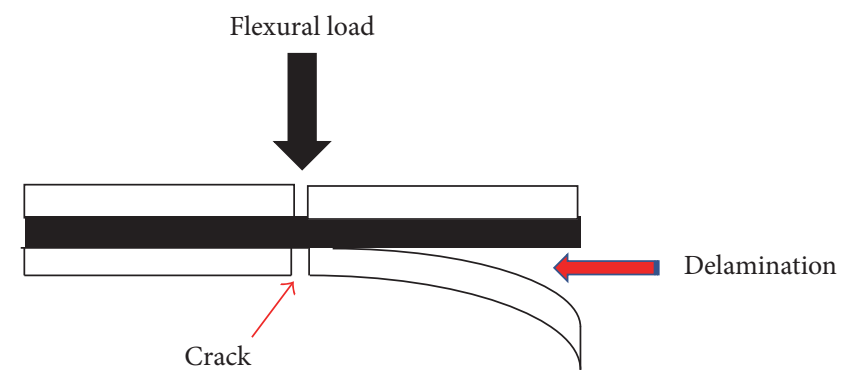

(b) Delamination after cracking

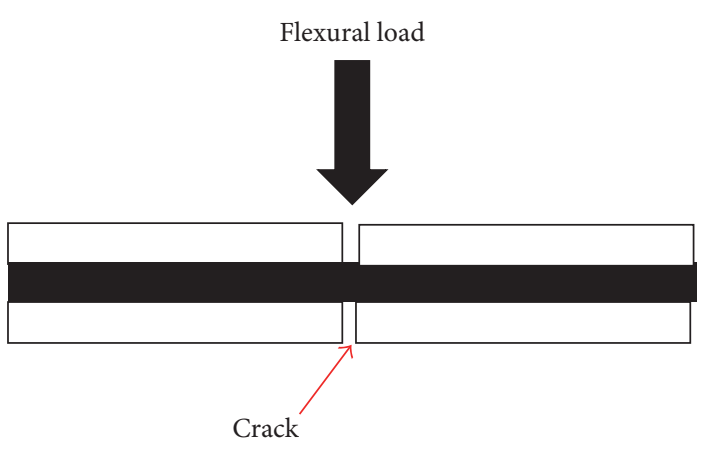

(c) Without delamination

Figure 8: Fracture mode after flexural tests.

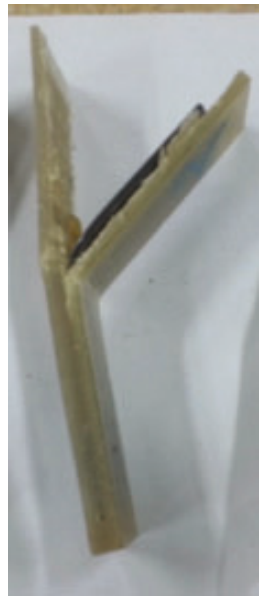

(a) Control

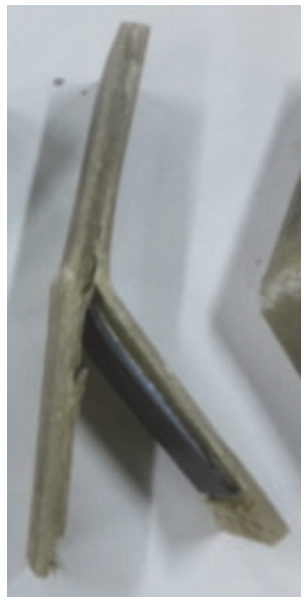

(b) Hole

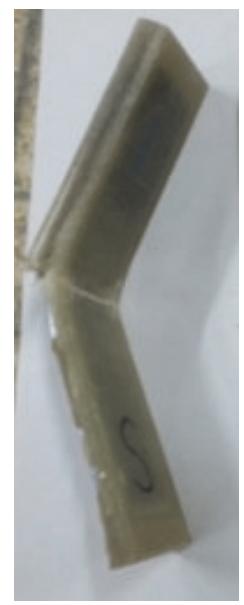

(c) Scratch

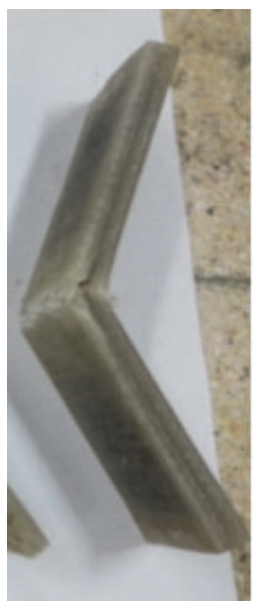

(d) Sand blast

FIGURE 9: Fracture deformation after flexural tests.

portion after the crack due to the flexural load (Figure 8(b)). In the third type, cracks due to the flexural load occur, but the interface delamination does not occur because of the excellent bond (Figure 8(c)). Figure 9 shows the type of fracture after the flexural strength test. Observation of the shape of fractured samples revealed that, in the case with no surface processing of the steel panel, the fracture occurred via interfacial delamination between the steel panel and the GFRP panel before the occurrence of a crack and splitting in the GFRP panel at the loading point [Figure 9(a)]. In contrast, in the cases of hole [Figure 9(b)] and scratch
[Figure 9(c)] processing, there were interfacial delamination at the interface where the steel panel and the GFPR panel adhere to each other and splitting via a crack at the loading point, which occurred at the same time. However, in the case of the sand blast [Figure 9(d)] processing, fracture by interfacial delamination at the interface between the steel panel and the GFRP panel did not occur, but splitting via a crack at the loading point did occur. These results verified that the steel panel surface processed by sand blasting had the highest performance. Taking these findings together, this study showed that the steel panel surface processing 


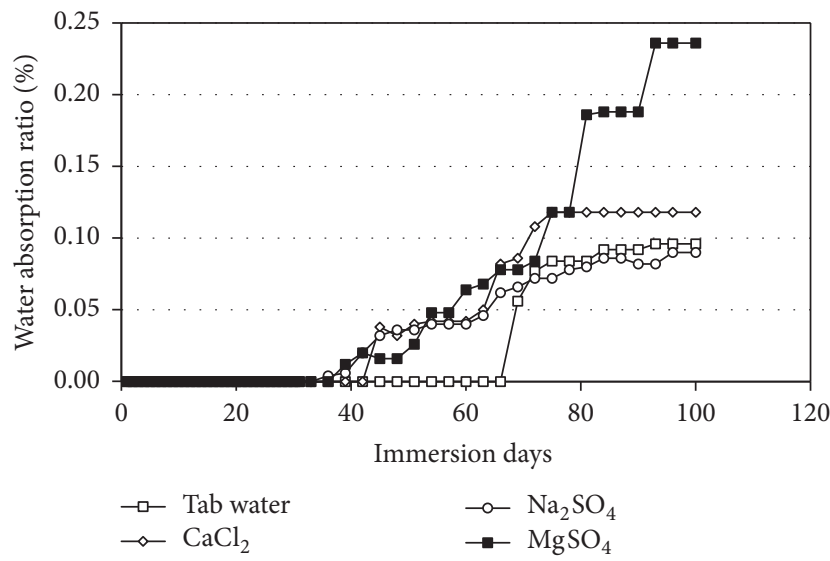

FIGURE 10: Absorption test results of hybrid panels.



FIGURE 11: Final absorption rate of hybrid panels.

method using sand blasting was superior. During the tests, test specimens with no surface processing were also tested for comparison and the results were analyzed.

5.2. Absorption Rates. For the moisture absorption behavior test, Figure 10 shows that the moisture absorption started during the period of 35-60 days of immersion. At 100 days, the moisture absorption ratio almost plateaued, indicating that almost no more moisture absorption occurred. Considering the moisture absorption ratio for concrete-reinforcing materials, previous research showed that, in the case of glass fiber using GFRP composite material immersed in an alkali solution, the final absorption ratio was about $2.0 \%$ or less, which presents no issues regarding the durability. It is difficult to generalize such results to this study, but this threshold is satisfied in all exposure conditions (Figure 11); this indicates that the influence of moisture absorption by the panels is not significant. Upon analyzing the detailed absorption ratio test results, upon exposure to tap water, the absorption ratio was $0.96 \%$. However, upon exposure to $\mathrm{CaCl}_{2}, \mathrm{Na}_{2} \mathrm{SO}_{4}$, and $\mathrm{MgSO}_{4}$ solutions, the absorption ratios were $0.12 \%, 0.09 \%$, and $0.24 \%$, respectively. The exposure to $\mathrm{MgSO}_{4}$ solution showed the greatest absorption ratio.

5.3. Flexural Strength after Accelerated Sulfate Environmental Conditions. To evaluate the influence of long-term exposure

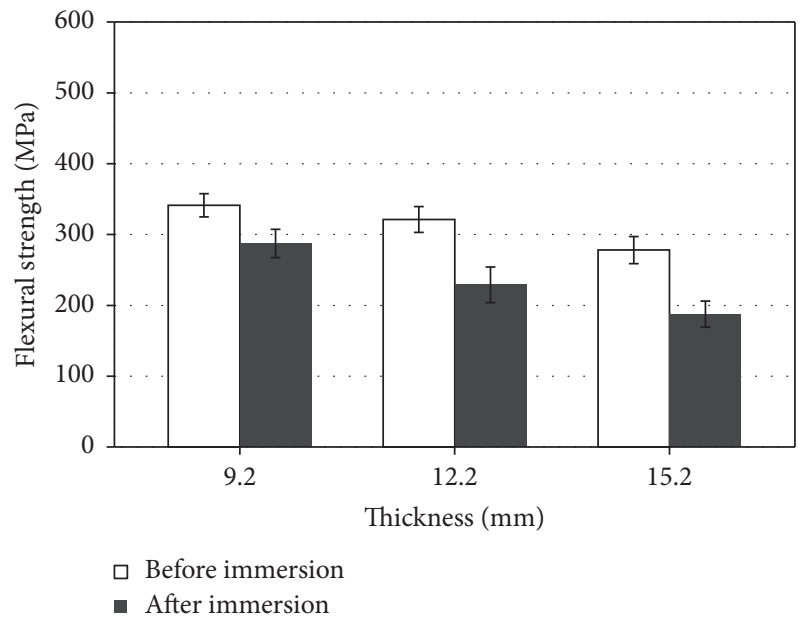

(a) Control

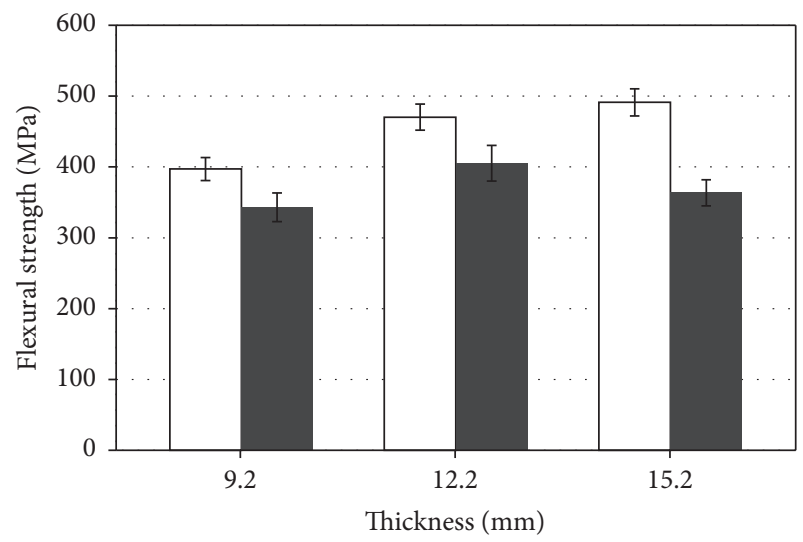

$\square$ Before immersion

- After immersion

(b) Sand blast



(c) Residual strength

FIGURE 12: Flexural test results of tap water immersions.

of the hybrid panel to humid conditions, after exposure to $60^{\circ} \mathrm{C}$ tap water for 50 days, a flexural strength test was performed. The long-term humidity exposure test results are shown in Figure 12. At hybrid panel thicknesses of 9.2, 12.2, 


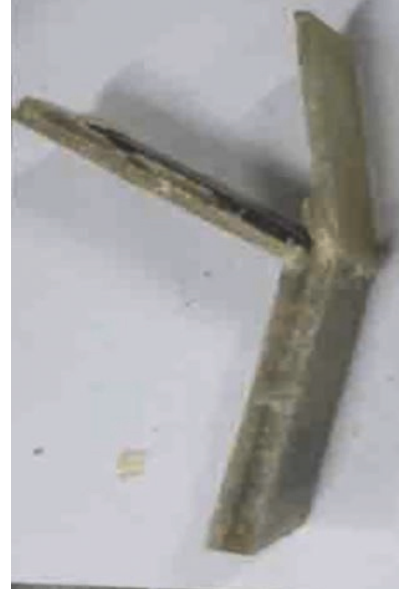

(a) $9.2 \mathrm{~mm}$ (plain)

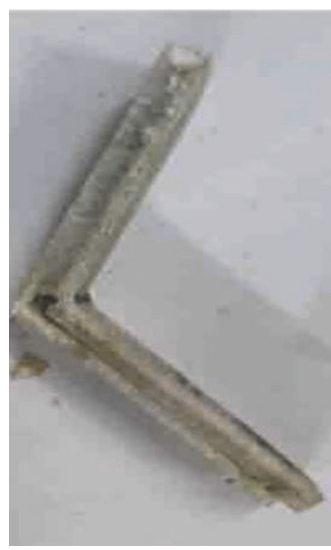

(d) $9.2 \mathrm{~mm}$ (sand blast)

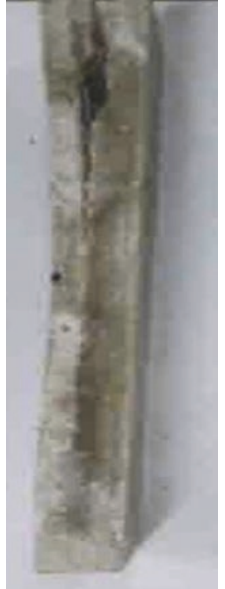

(b) $12.2 \mathrm{~mm}$ (plain)

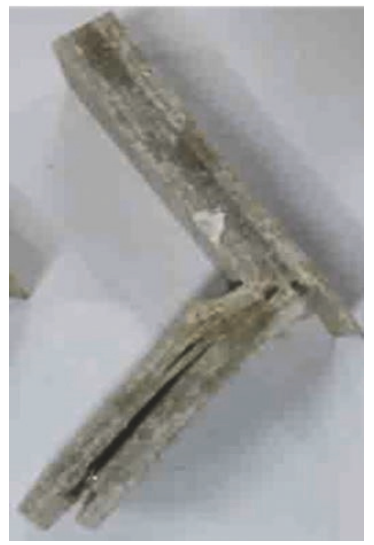

(e) $12.2 \mathrm{~mm}$ (sand blast)

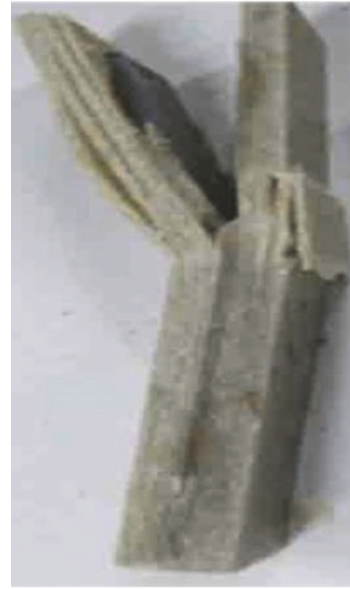

(c) $15.2 \mathrm{~mm}$ (plain)

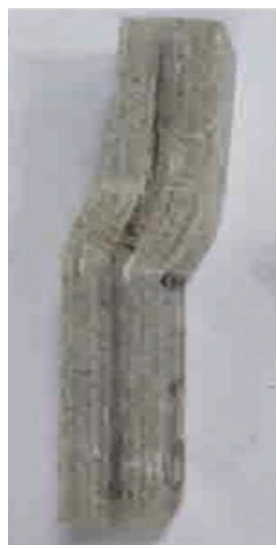

(f) $15.2 \mathrm{~mm}$ (sand blast)

FIGURE 13: Fracture deformation with thickness of hybrid panels after tap water immersions.

and $15.2 \mathrm{~mm}$, the hybrid panels without surface processing showed flexural strengths of 287.48, 228.98, and $187.60 \mathrm{MPa}$, respectively. The corresponding values for the silica surface spray-processed hybrid panels were $343.08,405.32$, and $363.51 \mathrm{MPa}$, respectively. In addition, the residual strength test results were all $65 \%$ or more, which met one of the criteria applied in this study. The test results obtained at panel thicknesses of 9.2, 12.2, and $15.2 \mathrm{~mm}$ with no processing of the panel surface were $84.22 \%, 71.27 \%$, and $67.45 \%$, respectively. The corresponding results for panels whose surfaces had been subjected to sand blast processing were $86.38 \%, 86.20 \%$, and $74.02 \%$, respectively. After long-term moisture exposure, all of the residual strengths satisfied the criterion of $>65 \%$. Generally, moisture in hybrid panels leads to degradation of the mechanical performance. The specific factors influencing the mechanical performance differ according to the degree of moisture absorption but generally include polymer resin and fiber type. If moisture is absorbed into the interface between fiber and polymer resin, very rapid fracture can occur. The study showed a tendency for decreased residual strength as the thickness of the GFRP panel increased. The reason for this is that, as the GFRP panel thickness increases, the polymer resin absorbs more moisture, which increases the possibility of fracture of the glass fiber interface. The type of fracture of the sample after a flexural test following exposure to tap water is shown in Figure 13. Regardless of the GFRP panel thickness, fracture via splitting occurred in all interfaces. In the case of sand blast processing, the fracture occurred in the interface between the steel panel and the GFRP panel, but compared to the panel with no surface processing, it showed significantly less interfacial delamination. In this study, the effects of exposure of the hybrid panel to a sulfate ion environment were considered. The deterioration test was performed using $\mathrm{Na}_{2} \mathrm{SO}_{4}$ and $\mathrm{MgSO}_{4}$ solutions. The test results for exposure to the $\mathrm{Na}_{2} \mathrm{SO}_{4}$ solution are shown in Figure 14. At hybrid panel thicknesses of 9.2, 12.2, and $15.2 \mathrm{~mm}$, the panel with no surface processing showed flexural strength levels of 239.92, 246.83, and 176.44 MPa, whilst the hybrid panel with silica surface spray processing showed levels of $310.90,386.52$, and $387.71 \mathrm{MPa}$, respectively. In addition, all of the residual strength test results were $60 \%$ or more, which fulfills the criterion set in this study. At hybrid panel thicknesses of 9.2, 12.2, and $15.2 \mathrm{~mm}$, the panel with no surface processing showed residual strength levels of 


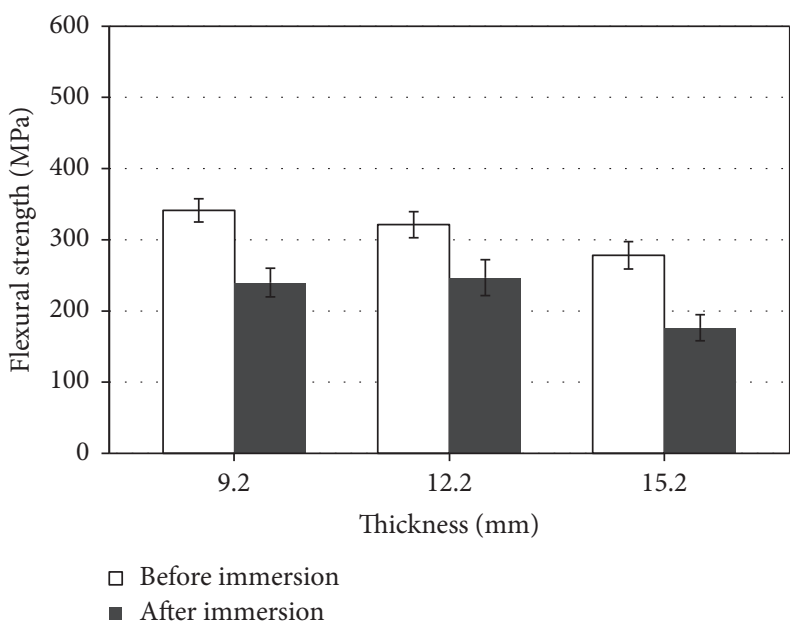

(a) Control

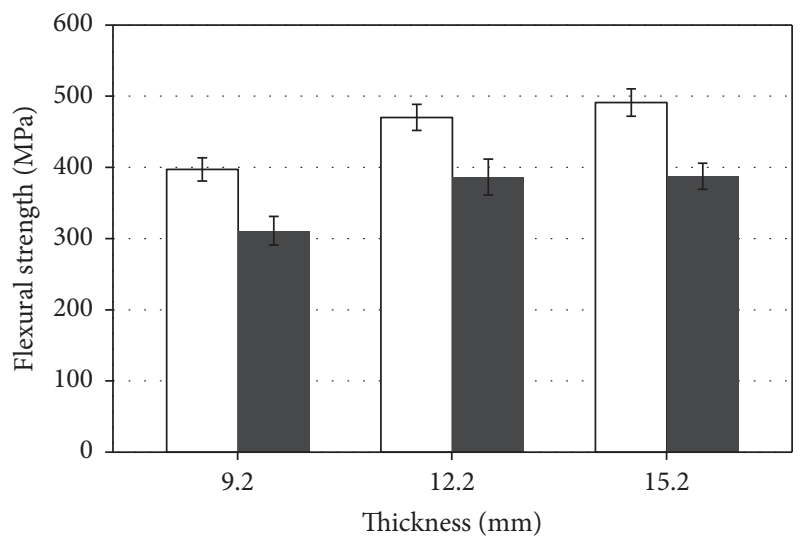

$\square$ Before immersion

- After immersion

(b) Sand blast

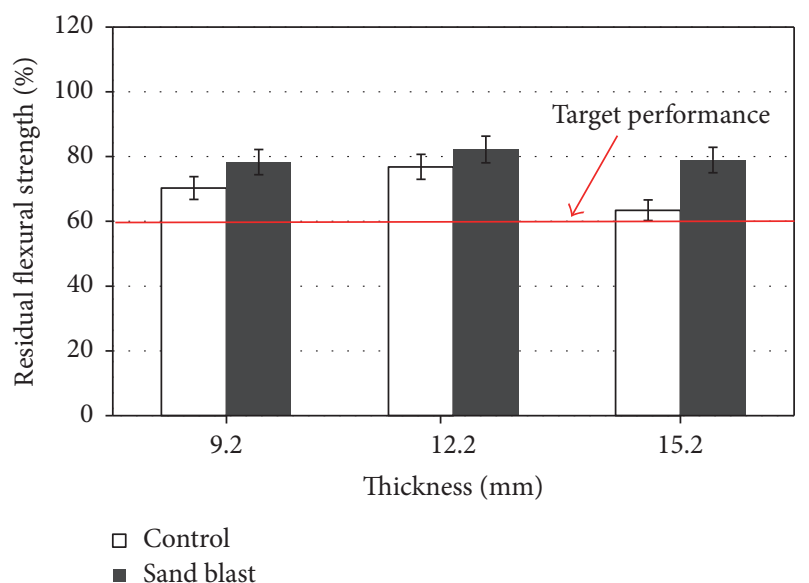

(c) Residual strength

FIgURE 14: Flexural test results of $\mathrm{Na}_{2} \mathrm{SO}_{4}$ solution immersions.

$70.29 \%, 76.83 \%$, and $63.44 \%$, whilst the corresponding results upon surface sand blast processing were $78.29 \%, 82.20 \%$, and $78.94 \%$, respectively. The test results upon exposure to $\mathrm{MgSO}_{4}$ solution are shown in Figure 15. At hybrid panel

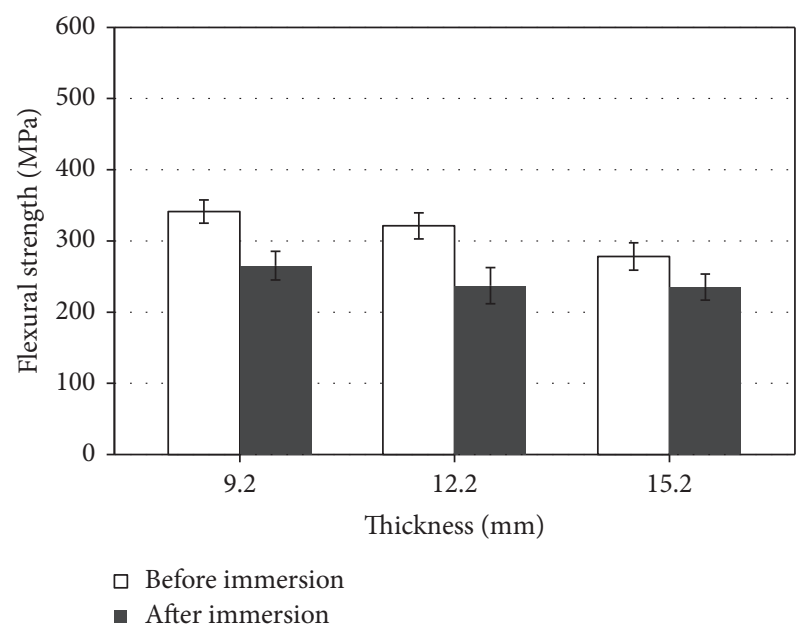

(a) Control

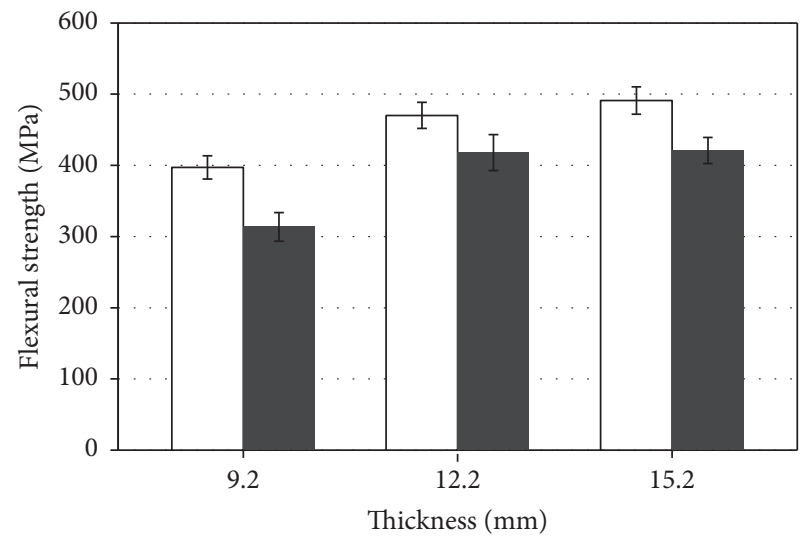

$\square$ Before immersion

- After immersion

(b) Sand blast



(c) Residual strength

FIgURE 15: Flexural test results of $\mathrm{MgSO}_{4}$ solution immersions.

thicknesses of 9.2, 12.2, and $15.2 \mathrm{~mm}$, the panel with no surface processing showed flexural strength levels of 221.37, 200.49, and 176.11 MPa, whilst for the hybrid panel with silica surface spray processing, the corresponding values were 


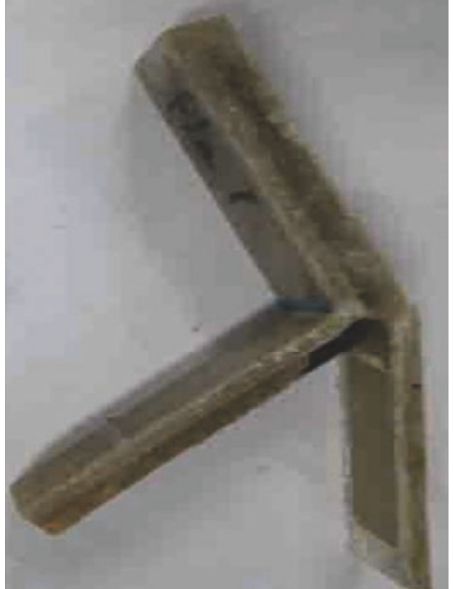

(a) $9.2 \mathrm{~mm}$ (plain)

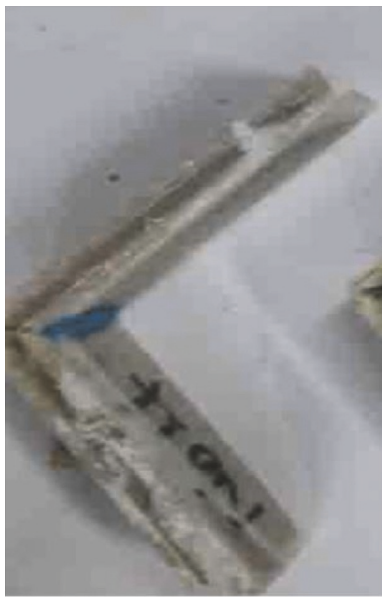

(d) $9.2 \mathrm{~mm}$ (sand blast)

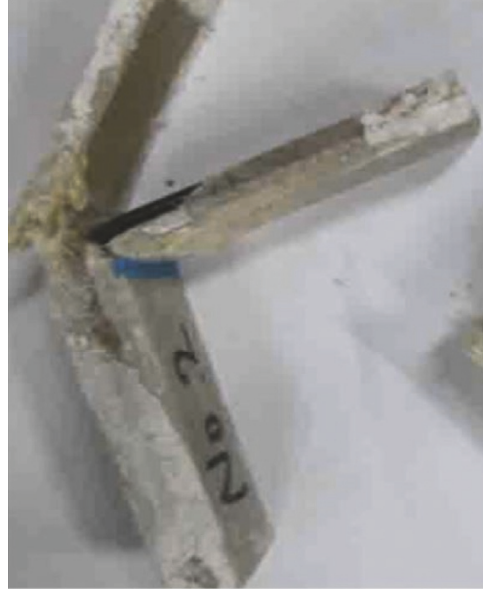

(b) $12.2 \mathrm{~mm}$ (plain)

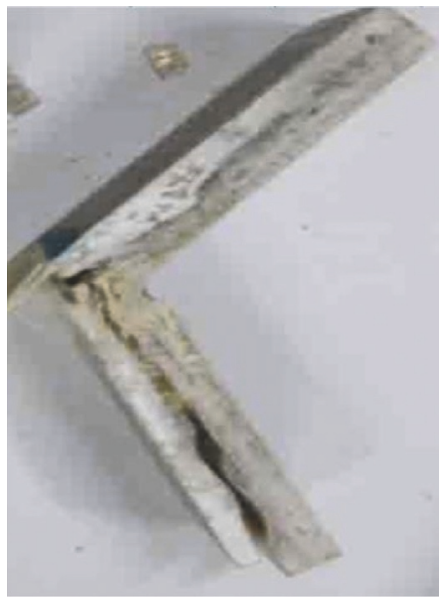

(e) $12.2 \mathrm{~mm}$ (sand blast)



(c) $15.2 \mathrm{~mm}$ (plain)

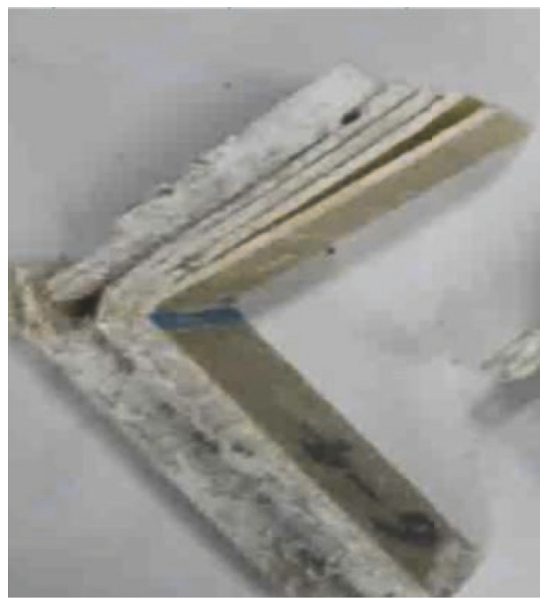

(f) $15.2 \mathrm{~mm}$ (sand blast)

FIGURE 16: Fracture deformation with thickness of hybrid panels after $\mathrm{Na}_{2} \mathrm{SO}_{4}$ solution immersions.

317.50, 380.54, and 447.10 $\mathrm{MPa}$, respectively. All of the residual strength test results were $60 \%$ or more, which fulfilled the criterion set in this study. At hybrid panel thicknesses of 9.2, 12.2, and $15.2 \mathrm{~mm}$, the panel with no surface processing showed residual strength levels of $64.85 \%, 62.41 \%$, and $63.32 \%$, whilst the corresponding results for surface sand blast processing were $79.95 \%, 80.93 \%$, and $91.04 \%$, respectively. Considering these test results, the strength of the hybrid panel when using the sand blast processing was excellent. In addition, all of the residual strength values were $65 \%$ or more. However, in the case without surface processing, all of the results were $65 \%$ or less, which did not satisfy the standard set here. This is considered to be due to the fact that if the adhesion strength is greater, it suppresses the penetration by sulfate solution into the interface, which has the effect of suppressing the fracture of the adhesion interface. Generally, decreased strength upon exposure to sulfate is influenced by both the sulfate damage itself and the moisture absorption occurring at the same time. In fact, it is known that the moisture absorption has a greater influence. In other words, the decrease in strength is caused specifically by the absorption of the sulfate solution, which has a greater influence than direct fracture by sulfate itself. However, since the level of moisture absorption for the sulfate solution was significantly greater than that for standard tap water, the decrease in strength could be greater. However, in this study, the matrix resin type and the fiber type were the same among the different samples, so the influence on the adhesion and the influence on the solution type were found to be the most significant. Therefore, the case with surface sand blast processing with greater adhesion strength showed outstanding resistance against sulfate damage. The types of sample fracture after the flexural test following exposure to $\mathrm{Na}_{2} \mathrm{SO}_{4}$ and $\mathrm{MgSO}_{4}$ solutions are shown in Figures 16 and 17. The results show that, regardless of the solution type and GFRP panel thickness, fracture via splitting occurred in all interfaces. However, in the case with sand blast processing, the fracture occurred in the interface between the steel panel and the GFRP panel, but when compared to the case with no surface processing, a significant decrease in interfacial delamination was shown. In addition, in the case of sand blast processing, the results showed that the fracture involved slow separation of the GFRP. Therefore, rather than interfacial 


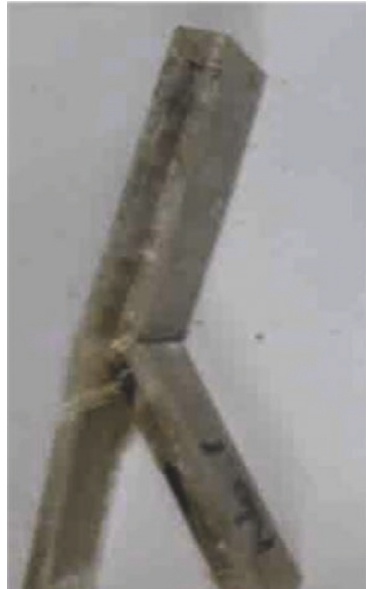

(a) $9.2 \mathrm{~mm}$ (plain)

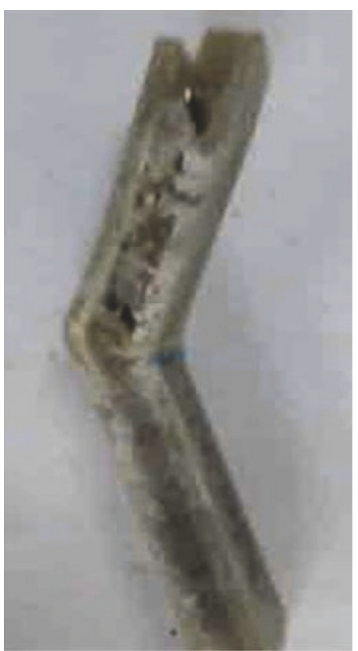

(d) $9.2 \mathrm{~mm}$ (sand blast)

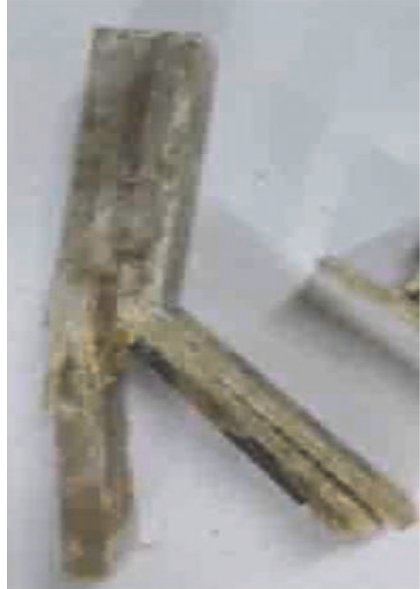

(b) $12.2 \mathrm{~mm}$ (plain)

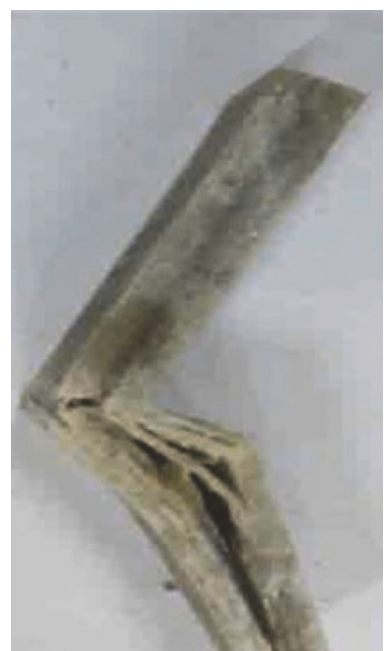

(e) $12.2 \mathrm{~mm}$ (sand blast)

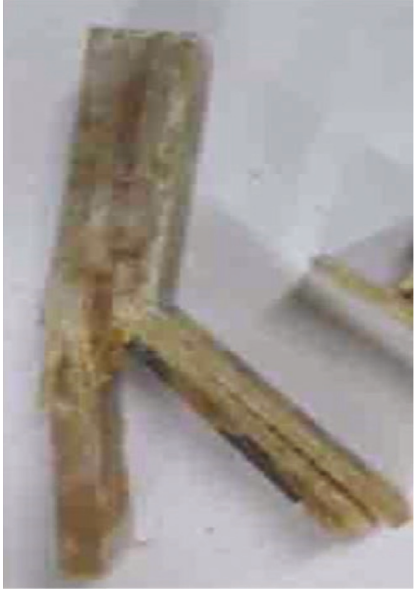

(c) $15.2 \mathrm{~mm}$ (plain)

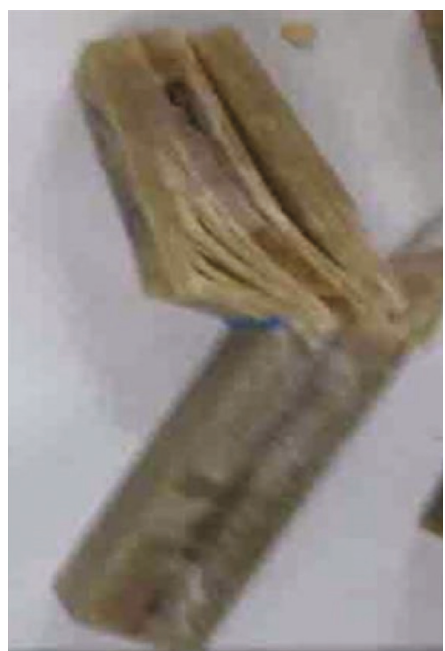

(f) $15.2 \mathrm{~mm}$ (sand blast)

FIGURE 17: Fracture deformation with thickness of hybrid panels after $\mathrm{MgSO}_{4}$ solution immersions.

failure, fracture of the glass fiber and interfacial delamination of the polymer resin occurred at the same time. The case with sand blast processing showed greater adhesive strength than the case with no surface processing, which showed an overall increase in flexural strength.

\subsection{Flexural Strength after Accelerated Calcium Chloride} Environment Conditions. The results of the test of exposure to an environment containing deicing material $\left(\mathrm{CaCl}_{2}\right)$ are shown in Figure 18. At hybrid panel thicknesses of 9.2, 12.2, and $15.2 \mathrm{~mm}$, the panels with no surface processing showed flexural strength levels of $265.25,237.22$, and $235.29 \mathrm{MPa}$, whilst the hybrid panels subjected to san blast processing showed levels of $313.68,417.91$, and $421.04 \mathrm{MPa}$, respectively. The results show that, as the hybrid panel thickness increased, the flexural strength of the case with no surface processing increased at $12.2 \mathrm{~mm}$ but decreased at $15.2 \mathrm{~mm}$. However, in the case of the surface sand blast processing, the adhesion strength increased as the thickness increased. The reason for these results is that sand blast processing is associated with relatively high adhesion strength; thus it suppresses the penetration of deicing material into the interface between the steel panel and the GFRP panel. This confers outstanding resistance against fracture via failure of adhesion at the interface. In addition, all of the residual strength test results were $60 \%$ or more, which satisfied the criterion set in this study. At hybrid panel thicknesses of 9.2, 12.2, and $15.2 \mathrm{~mm}$, the residual strength of the panel with no surface processing were $77.71 \%, 73.84 \%$, and $84.60 \%$, whilst the corresponding values in the case with surface sand blast processing were $78.99 \%$, $88.88 \%$, and $85.73 \%$ respectively. In addition, regarding the residual adhesion strength at the same panel thickness, the surface sand blast processing produced the highest result, which shows that the interface's adhesive strength influences the penetration of deicing material. The types of fracture after the flexural test upon exposure to $\mathrm{CaCl}_{2}$ solution are shown in Figure 19. The results show that, regardless of the GFRP panel thickness, fracture via splitting occurred at all interfaces. However, in the case of sand blast processing, fracture occurred at the interface between the steel panel and the 


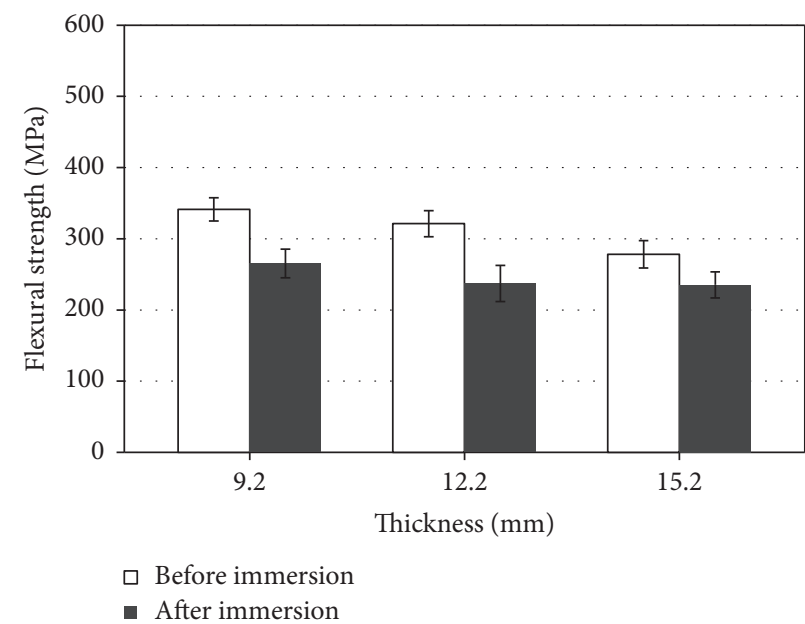

(a) Control

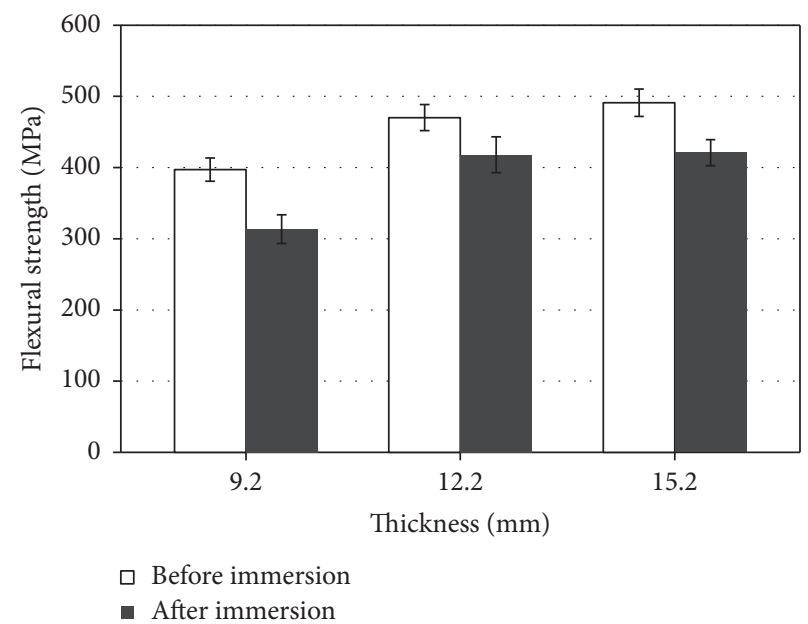

(b) Sand blast

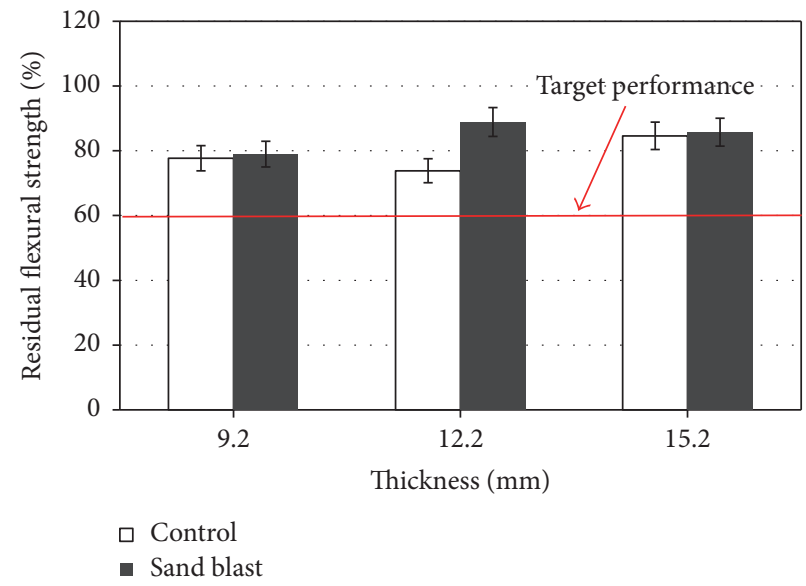

(c) Residual strength

FIgURE 18: Flexural test results of $\mathrm{Ca}_{2} \mathrm{Cl}_{2}$ solution immersions.

GFRP panel, but upon comparison to the case with no surface processing, the sand blast processing specimens showed a significant decrease in interfacial delamination. This means that the adhesive strength upon sand blast processing was greater than that upon no surface processing, which resulted in an overall increase in flexural strength.

\section{Conclusions}

In this study, a hybrid panel was developed by combining a steel panel and GFRP panels for application to an improved movable weir; its performance was also evaluated. The results of this study can be summarized as follows:

(i) As a result of the flexural test according to the method of processing of the steel panel surface, the sand blasted test specimen's flexural strength results were the best. The test specimen (hole) with a hole in its surface showed the lowest strength.

(ii) As a result of observation of the fracture shape, when the surface treatment was not performed, the interface delamination occurred before the cracking. In case of surface hole and scratch, interfacial delamination occurred after cracking. In case of sand blast treatment, cracking occurred but interface delamination did not occur. Therefore, the sandblasted specimen showed the highest flexural performance.

(iii) The final absorption ratio test results showed the greatest absorption ratio for $\mathrm{MgSO}_{4}$ solution, whilst the smallest absorption ratio was shown for tap water. Also, in this study, absorption ratios were $2.0 \%$ or less, at the all environments.

(iv) The results of the accelerated deterioration tests performed in different accelerated deterioration environments showed that if the steel panel surface is sand blasted, it satisfies the criterion of residual strength of $65 \%$ or more, so again there would be no problems regarding durability. However, in the case with no surface processing, upon exposure to $\mathrm{MgSO}_{4}$ solution, it did not satisfy the residual strength criterion of $65 \%$ or more. 


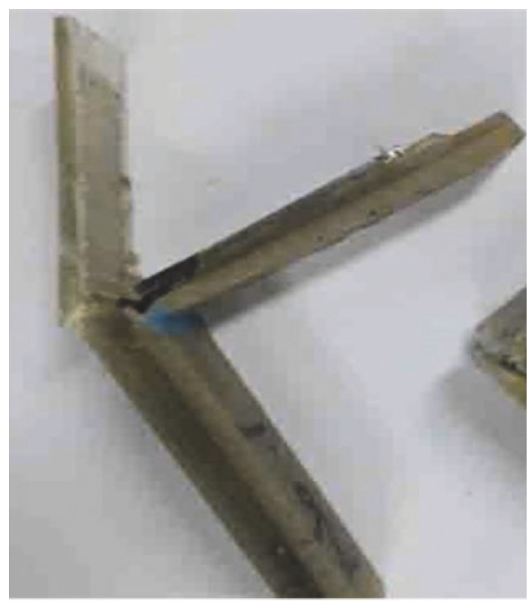

(a) $9.2 \mathrm{~mm}$ (plain)

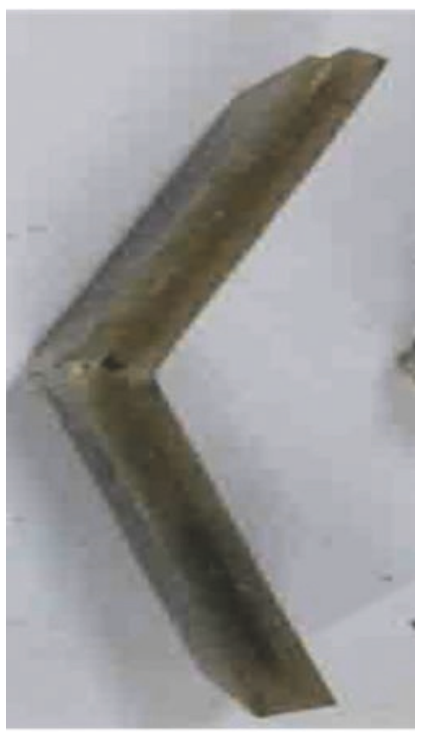

(d) $9.2 \mathrm{~mm}$ (sand blast)



(b) $12.2 \mathrm{~mm}$ (plain)

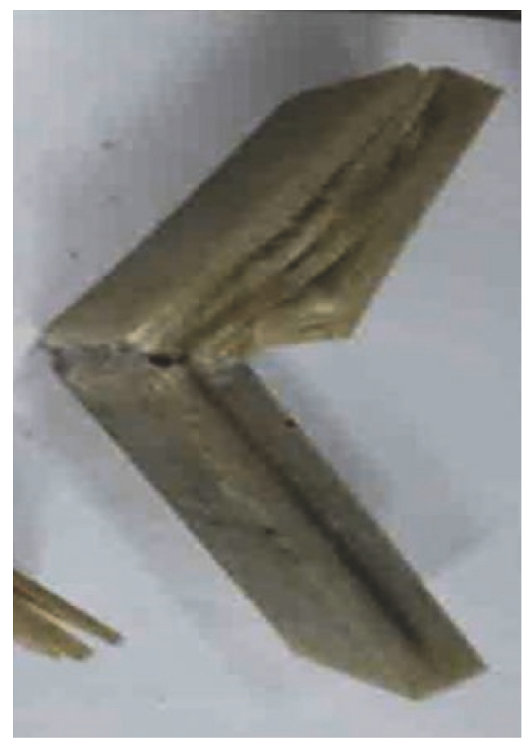

(e) $12.2 \mathrm{~mm}$ (sand blast)

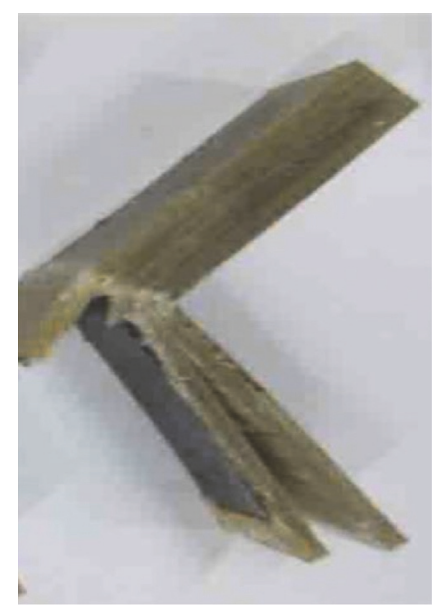

(c) $15.2 \mathrm{~mm}$ (plain)

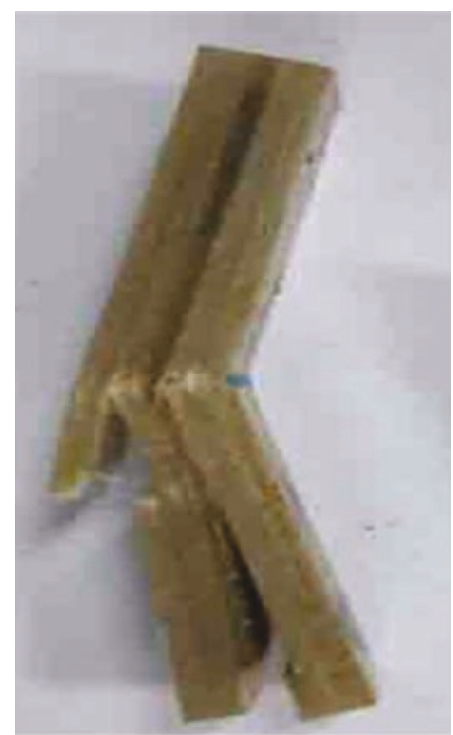

(f) $15.2 \mathrm{~mm}$ (sand blast)

FIGURE 19: Fracture deformation with thickness of hybrid panels after $\mathrm{Ca}_{2} \mathrm{Cl}_{2}$ solution.

\section{Conflicts of Interest}

The authors declare that there are no conflicts of interest regarding the publication of this paper.

\section{Acknowledgments}

This work was supported by Korea Institute of Planning and Evaluation for Technology in Food, Agriculture, Forestry and Fisheries (IPET) through Agri-Bio Industry Technology Development Program, funded by Ministry of Agriculture, Food and Rural Affairs (MAFRA) (316034-3). Also, this research was supported by a Grant (code-14TBIP-C07399301-000000) from Technology Business Innovation Program (TBIP) funded by Ministry of Land, Infrastructure and Transport of Korean Government.

\section{References}

[1] C. G. Yeo, Y. H. Kim, G. S. Seo, and J. W. Song, "The study for Hydraulic Influence by installing Movable Weir," in Conference of the Korean Society of Civil Engineers in 2009, pp. 1452-1455, 2009.

[2] H. J. Park, Study on the Effect of Weir on Stream Flow, Konkuk University, Seoul, 2010.

[3] P. S. Kim, S. J. Kim, J. H. Shim, and H. J. Park, "The study of Flood Hazard Mitigation Effect for Movable Weir," in Proceedings of the Korea Water Resources Association Conference (KWRA 10), pp. 808-812, 2010.

[4] J. K. Kim, The Variation of Flow Characteristics by Installing Improved Movable Weir in a River, Inchon University, Inchon, 2006.

[5] J. W. Lee, C. G. Park, J. O. Kim, and S. K. Lee, "Durability characteristics of glass fiber reinforced polymer composite 
clapping plates for application of rubber dam," Journal of The Korean Society of Agricultural Engineers, vol. 53, no. 5, pp. 1723, 2011.

[6] K. W. Kim, H. J. Kwon, P. S. Kim, and C. G. Park, "Flexural and interfacial bond properties of hybrid steel/glass fiber reinforced polymer composites panel gate with steel gate surface deformation for improved movable weir," Journal of The Korean Society of Agricultural Engineers, vol. 57, no. 2, pp. 57-66, 2015.

[7] G. W. Choi, S. J. Byeon, Y. K. Kim, and S. U. Cho, "Characteristics of discharge capacity due to the variation of downstream water level of the multifunctional movable weir," Journal of Korean Society of Hazard Mitigation, vol. 8, no. 3, pp. 117-122, 2008.

[8] J. W. Choi, H. J. Joo, J. M. Kim, and S. J. Yoon, "An analytical study on the structural performance evaluation of the multistage overturing movable gate," Journal of Korean Society of Steel Construction, vol. 25, no. 6, pp. 613-622, 2013.

[9] B. J. Choi, A study on the effect of weir on stream flow and ground water, Seoul National University of Science and Technology, Seoul, Republic of Korea, 2011.

[10] K. S. Lee, C. Jang, N. Lee, and S. J. Ahn, "Analysis of flow characteristics of the improved-pneumatic-movable weir through the laboratory experiments," Journal of Korea Water Resources Association, vol. 47, pp. 1007-1015, 2014.

[11] T. Hwang and J. Kim, "Analysis of fluid-structure interaction for development of korean inflatable rubber dams for small hydropower," Journal of the Korean Society of Marine Engineering, vol. 32, no. 8, pp. 1221-1230, 2008.

[12] H. H. Kim and T. G. Hwang, "Analysis of fluid-structure interaction for development of inflatable improved movable weirs for small hydropower," Journal of Fluid Machinery, vol. 11, pp. 86-92, 2008.

[13] ACI 440H, Guide for the Design and Construction of Concrete Reinforced with FRP Bars, Farmington Hills, Mich, USA, 2000.

[14] P. Feng, J. Wang, Y. Wang, D. Loughery, and D. Niu, "Effects of corrosive environments on properties of pultruded GFRP plates," Composites Part B: Engineering, vol. 67, pp. 427-433, 2014.

[15] J. Zhou, X. Chen, and S. Chen, "Durability and service life prediction of GFRP bars embedded in concrete under acid environment," Nuclear Engineering and Design, vol. 241, no. 10, pp. 4095-4102, 2011.

[16] J. M. Sousa, J. R. Correia, S. Cabral-Fonseca, and A. C. Diogo, "Effects of thermal cycles on the mechanical response of pultruded GFRP profiles used in civil engineering applications," Composite Structures, vol. 116, no. 1, pp. 720-731, 2014.

[17] C. G. Park and J. P. Won, "Effect of acceterated aging on the tensile and bond properties of frp rebar for concrete," Journal of The Korean Society of Agricultural Engineers, vol. 47, no. 2, pp. 73-84, 2005.

[18] S. Aldajah, G. Alawsi, and S. A. Rahmaan, "Impact of sea and tap water exposure on the durability of GFRP laminates," Materials and Design, vol. 30, no. 5, pp. 1835-1840, 2009.

[19] Y. Miyano, M. Nakada, and N. Sekine, "Accelerated testing for long-term durability of GFRP laminates for marine use," Composites Part B: Engineering, vol. 35, pp. 497-503, 2004.

[20] H. C. Biscaia, M. A. G. Silva, and C. Chastre, "An experimental study of GFRP-to-concrete interfaces submitted to humidity cycles," Composite Structures, vol. 110, pp. 354-368, 2014.

[21] C. G. Park, J. P. Won, and J. K. Yoo, "Long-term effect of chemical environments on FRP reinforcing bar for concrete reinforcement," Journal of the Korea Concrete Institute, vol. 15, pp. 811-819, 2003.

[22] F. Micelli and A. Nanni, "Mechanical properties and durability of FRP rod," Report of CIES, 00-22, Department of Civil Engineering, University of Missouri-Rolla, Rolla, Missouri, USA, 2001.

[23] M. Giampaoli, V. Terlizzi, M. Rossi, G. Chiappini, and P. Munafò, "Mechanical performances of GFRP-steel specimens bonded with different epoxy adhesives, before and after the aging treatments," Composite Structures, vol. 171, pp. 1455-157, 2017.

[24] H.-Y. Kim and S.-Y. Lee, "A steel-reinforced hybrid GFRP deck panel for temporary bridges," Construction and Building Materials, vol. 34, pp. 192-200, 2012.

[25] M. Heshmati, R. Haghani, and M. Al-Emrani, "Durability of bonded FRP-to-steel joints: Effects of moisture, de-icing salt solution, temperature and FRP type," Composites Part B: Engineering, vol. 119, pp. 153-167, 2017.

[26] D. Linghoff, R. Haghani, and M. Al-Emrani, "Carbon-fibre composites for strengthening steel structures," Thin-Walled Structures, vol. 47, no. 10, pp. 1048-1058, 2009.

[27] R. Haghani and M. Al-Emrani, "A new design model for adhesive joints used to bond FRP laminates to steel beams-Part A: background and theory," Construction and Building Materials, vol. 34, pp. 486-493, 2012.

[28] M. Heshmati, R. Haghani, and M. Al-Emrani, "Effects of moisture on the long-term performance of adhesively bonded FRP/steel joints used in bridges," Composites Part B: Engineering, vol. 92, pp. 447-462, 2016. 

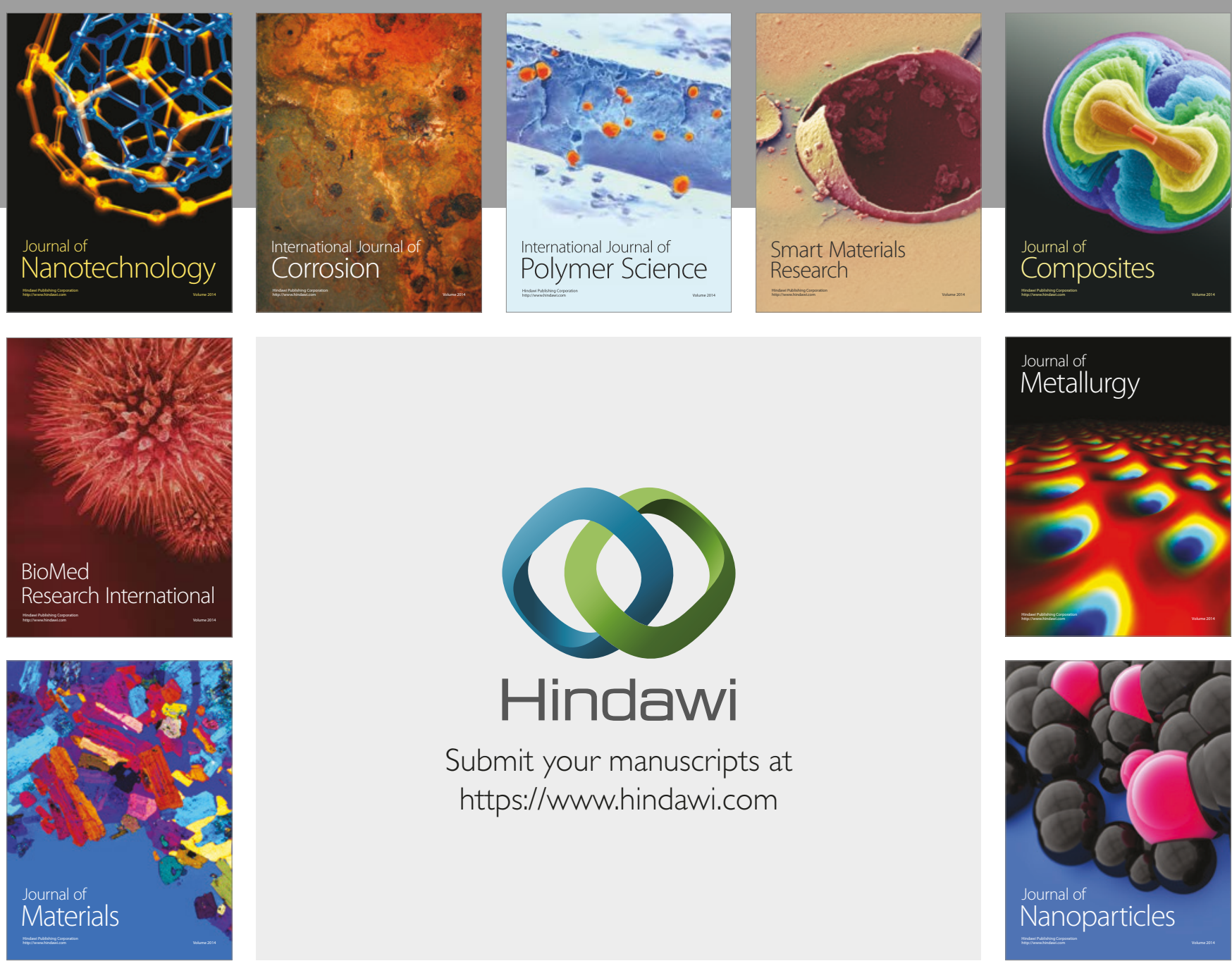

\section{Hindawi}

Submit your manuscripts at

https://www.hindawi.com
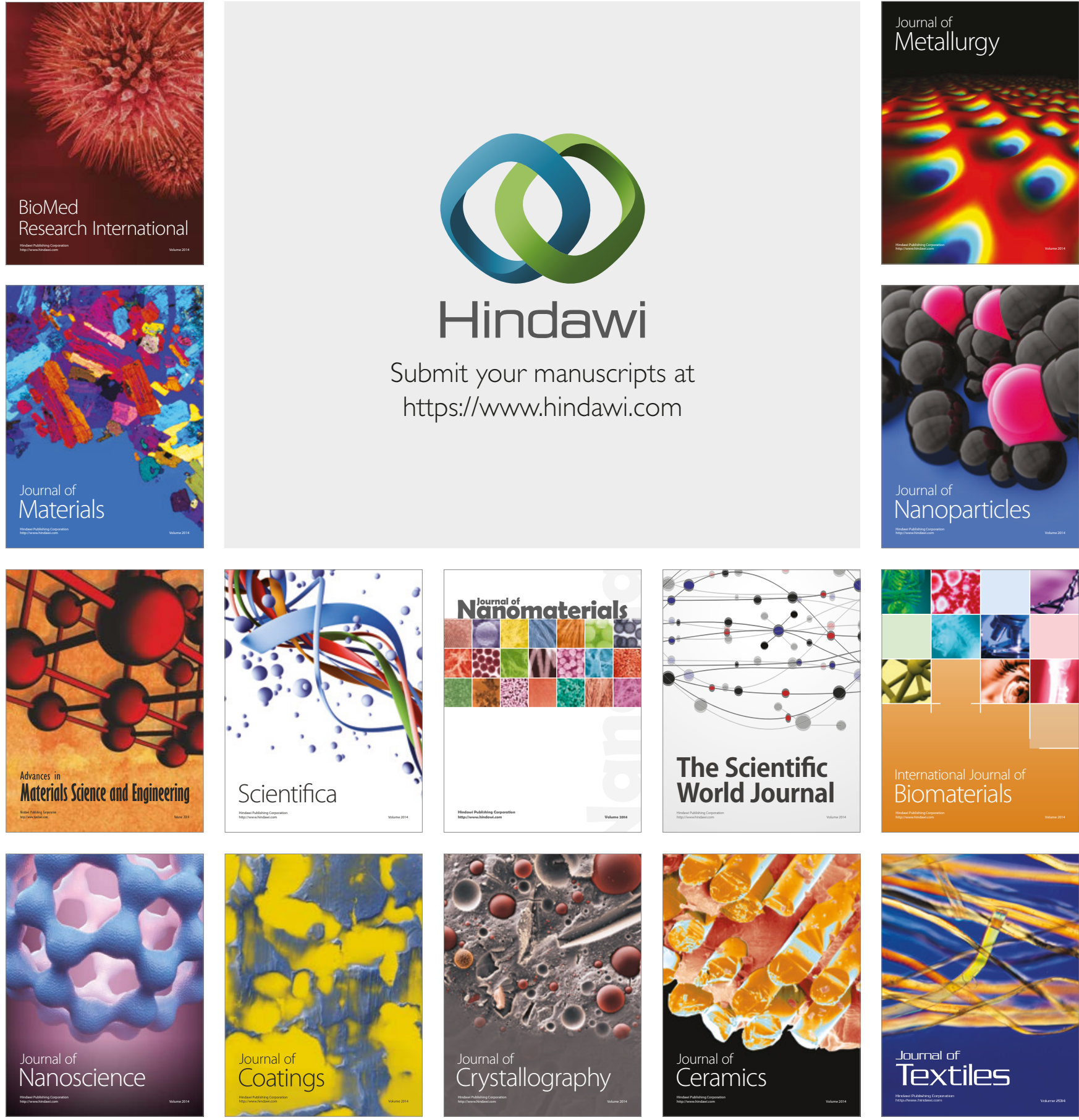

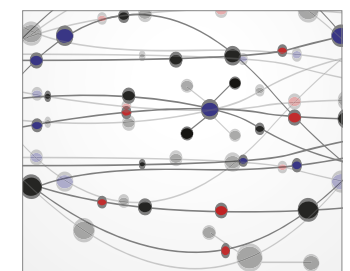

The Scientific World Journal
